\title{
Does rate of weight regain predict premature discontinuation of treatment during outpatient cognitive-behavioural therapy for eating disorders?
}

\author{
Amy Lampard ${ }^{1 *}$, Olivia Carter ${ }^{1}$, David Erceg-Hurn², Bronwyn Raykos², Anthea Fursland ${ }^{2}$ \\ From 2015 ANZAED Conference: Riding the Waves to Recovery \\ Surfers Paradise, Australia. 21-22 August 2015
}

Between $20-51 \%$ of eating disorder clients in inpatient settings and $29-73 \%$ in outpatient settings prematurely discontinue treatment. Research has attempted to address this problem by identifying the client characteristics upon entering treatment that predict dropout, but this approach has failed to identify consistent predictors of treatment dropout. Processes that occur early in treatment, such as early weight gain, may be important to consider as predictors of treatment dropout. Weight restoration is a primary goal of treatment for anorexia nervosa and may also be important in patients with bulimia nervosa who are weight suppressed. Previous research has explored the optimal rate of weight gain, but to our knowledge, no research has considered rate of weight gain as a predictor of risk for treatment dropout. Using weekly assessments of body mass index, the current research therefore aimed to identify whether a rapid rate of weight gain in the early stages of outpatient cognitive-behavioural therapy for eating disorders (CBT-E) is associated with a greater risk of treatment dropout. Participants were adult clients who entered CBT-E treatment for an eating disorder at an outpatient mental health service in Perth, Western Australia. Results will contribute to knowledge of early indicators of risk for treatment dropout.

\section{Authors' details}

${ }^{1}$ School of Psychology and Speech Pathology, Curtin University, Australia.

${ }^{2}$ Centre for Clinical Interventions, Australia.
Published: 23 November 2015

doi:10.1186/2050-2974-3-S1-043

Cite this article as: Lampard et al:: Does rate of weight regain predict premature discontinuation of treatment during outpatient cognitivebehavioural therapy for eating disorders? Journal of Eating Disorders 2015 3(Suppl 1):043.

* Correspondence: amy.lampard@curtin.edu.au

'School of Psychology and Speech Pathology, Curtin University, Australia Full list of author information is available at the end of the article

Submit your next manuscript to BioMed Central and take full advantage of:

- Convenient online submission

- Thorough peer review

- No space constraints or color figure charges

- Immediate publication on acceptance

- Inclusion in PubMed, CAS, Scopus and Google Scholar

- Research which is freely available for redistribution
( Biomed Central 